\title{
Distributed Generation: Definitions, Benefits, Technologies \& Challenges
}

\author{
Eltaib Said Elmubarak ${ }^{1}$, Ali Mohamed Ali ${ }^{2}$ \\ ${ }^{1}$ Alzaim Alazhari University, Khartoum, Sudan \\ ${ }^{2}$ Omdurman Alahlia University, Khartoum, Sudan
}

\begin{abstract}
High levels of penetration of distributed generation (DG) are a new challenge for traditional electric power systems. Power injections from DGs change network power flows, modifying energy losses and voltage profile of the system. This paper starts from the observation that there is a renewed interest in small-scale electricity generation. The author start with a survey of existing small-scale generation technologies and then move on with a discussion of the major benefits and issues of small scale electricity generation. An attempt is made to define the latter concepts more precisely. It appears that there is no consensus on a precise definition as the concept encompasses many technologies and applications. In a final section some of the current challenges and activities around interconnected these resources to the utility grid.
\end{abstract}

Keywords: Dispersed Generation, Grid connected, centralized electricity generation, Renewable energy, Micro turbine

\section{Introduction}

In recent years dispersed generation has been broadly used and are expected to become in the future electric power systems an important way for exploiting distributed energy resources or for supplying associated demands of electricity and heat (cogeneration). DG power plants are relatively small usually in $\mathrm{kw}$ to $\mathrm{Mw}$ range are generally connected to the grid at substation, distribution feeder or customer loads at customer premises and many of them make use of new technologies which generate power in form of DC (photovoltaic, Fuel cell,...) or in the form of AC at frequency different from the required $50 \mathrm{~Hz}$ (Wind generators, Microturbine ,...). In these cases voltage source convertors are needed in order to interface and join the smaller power source to the main Grid.

There is a major paradigm shift going on in the design and operation of power systems. Electrical networks of the past included a relatively small number of large power plants. However due to environmental and economical concerns this situation has started to change. The number of generators that use renewable energy sources (such as wind and photovoltaics) and have rather low rated power is increasing. Besides that also small generator that use conventional energy sources but in a more efficient way than previously designed generators appear nowadays. Most of them are connected to the distribution network level and referred to as distributed or dispersed generation (DG). These changes will greatly influence the power system. Distribution networks can no longer be considered as passive. In future it will not be possible to use simple equivalents of distribution networks for power system dynamic modeling. The large variety of DG types adds to the complexity of the problem.

Distributed generation for the moment loosely defined as small-scale electricity generation. It is a fairly new concept in the economics literature about electricity markets but the idea behind it is not new at all. In the early days of electricity generation distributed generation was the rule not the exception. The first power plants only supplied electricity to customers in the close neighborhood of the generation plant.
In the last decade however technological innovations and changing economic and regulatory environments have resulted in a renewed interest for distributed generation. This is confirmed by the IEA [21] who lists five major factors that contribute to this evolution i.e. developments in distributed generation technologies, constraints on the construction of new transmission lines, increased customer demand for highly reliable electricity, the electricity market liberalization and concerns about climate change. But Pepermans et.al.[20] reduced it to two major driving forces i.e electricity market liberalization and environment concerns. [7] gave standards that apply to the distributed generation (DG) products, namely the generators themselves and the interface products, as well as the requirements for their installation in terms of settings, performance and protection. This review provides a comparison of the scopes of various national and international DG related standards. Authors categorized distributed generators into two types:

- Rotating machine-based

- Static power converter-based systems

Since the former type is very conventional and largely used in the power industry they are relatively well known and although in the case of distributed generation the generators will be much smaller than those used traditionally in the industry, they remain since the former type is very conventional and largely used in the power industry they are relatively well known and although in the case of distributed generation the enerators will be much smaller than those used traditionally in the industry, they remain of the same technology. Therefore in this review only the standards for the relatively newer type of $\mathrm{DG}$ and the static power converter-based systems are presented.

Generators making use of static power converters fall into two categories:

- The ones that only produce DC

- The ones that produce AC but cannot (for practical or performance reasons) be synchronized to the grid. 


\section{International Journal of Science and Research (IJSR) \\ ISSN (Online): 2319-7064 \\ Index Copernicus Value (2013): 6.14 | Impact Factor (2014): 5.611}

Photovoltaics and fuel cells fall in the first category. These sources can only generate DC power and will require an inverter to be connected to the grid. On the other hand sources such as wind turbines and gas micro-turbines are rotating machines and theoretically could be (and in many large-scale systems are) synchronized with and feed the grid with electrical power via a rotating alternator. However for practical reasons such as getting rid of a complex gear-box or allowing the speed to vary, the use of a power converter stage is deemed to be a good choice.

\section{Material \& Methods}

\subsection{DG Definitions}

For the above mentioned technologies authors give standards. By nature generators coupled through static power converters will have a behavior that differs from rotating machines mainly with respect to its inertia and peak current capability. The low inertia of inverter-based systems allows for fast on/off transitions and on-the fly compensation of power quality issues while its limited peak current capability will prevent damage to equipment downstream. However this also means less support during grid perturbation and less capability to clear faults which may jeopardize protection coordination schemes. [7] Give various standards guiding the safety aspects of power converter in Canada and USA as well as at international level. And also give DG interconnection Standards.

A short survey of literature shows that there is no consensus. This is confirmed by International Environment and Development Research Centre (CIRED-1999) on the basis of a questionnaire submitted to the member countries [20]. Some countries define DG on the basis of voltage level where as other start from generation units are connected to the distributed networks. This is also the case for definition used by Internal Energy Agency (IEA-2002) [21] which sees distributed generation as units producing power on a customer's site or within local distribution network. IEA however makes no reference to the generating capacity level as opposed to all other definitions. Many definitions of DG exist allowing for a wide range of possible generation schemes. A simple definition has been provided by the European Commission as "a source of electric power connected to the distribution network or the customer side" [15]. Some definitions allow for the inclusion of larger scale cogeneration units or large wind farms connected to the transmission grid other put the focus on small-scale generation units connected to the distribution grid. All these definitions suggest that at least the small -scale generation units connected to the distribution grid are to considered as part of DG. Moreover generation units install close to the load or at customer side of the meter are also commonly identified as DG. This latter criterion partially overlaps with the first as most of generation units on customer sites are also include somewhat larger generation units installed on customer sites but connected to the transmission grid. This leads to the definition proposed by Ackermann et al.[22] who define distributed generation in terms of connection and location rather than generation capacity. They define a distributed generation source as an electric power generation source connected directly to the distribution network or on the customer side of meter. This definition puts no limit on the technology or capacity of potential distributed generation application. The Institute of Electrical and Electronics Engineers Inc (IEEE) has defined distributed generation (DG) as the generating of electricity by facilities that are sufficiently smaller than central generating plants so as to allow interconnection at nearly any point in a power system. International Council on Large Electricity Systems (CIGRE) has a Working Group on DG. It defined DG as all generation units with a maximum capacity of 100 MW usually connected to the distribution network that are neither centrally planned nor dispatched [15]. DG is usually classified according to the technologies used (e.g. renewable or fossil fuel based), generated power type, supply duration, capacity etc. DG is also categorized for specific applications in the electric system. Some of the most common applications for DG include standby, stand alone, rural and remote applications, peak load shaving, combined heat and power and base load.

James A. Momoh et al.[34 ] defined DG as " small electric generation plants using either combustion-based technologies such as reciprocating engines and turbines or non-combustion based technologies such as fuel cells located on or near end-users and are characterized as renewable or cogeneration non-dispatched sources. Types of DGs include Micro-turbine, Gas Internal Combustion Engine, Fuel Cells, Solar Photovoltaic, Small Wind Turbine, Large Wind Turbine, Combustion Turbines and Combined-Cycle System. The sizes range from a few $\mathrm{kW}$ to over $20 \mathrm{MW}$ capacities depending on the application needs ". [30 ] Gave an overview of DG connected to the grid. The work basic on his experiences in worked on distributed generation (DG) connected to the transmission and distribution grids of Ontario Hydro. Author discuss types of DG's, Methodology of connection to the grid minimizing the cost impact to the customers, system Groundings, faults and their effects protective relaying control and metering and harmonics and resonance.

There are many terms referring to DG such as "dispersed generation", "embedded generation", "decentralized generation" and "distributed decentralized generation". In the International Electrotechnical Vocabulary (IEC /1999/CDV:2006) the terms "embedded generation", "distributed generation" and "disperse generation" have been defined together as " generation of electric energy by sources which are connected in the power distribution system". The terms "small scale embedded generator" and "micro generator" have been defined together as "source of electric energy and all associated interface equipment able to be connected to a regular electric circuit in a low voltage electrical installation and designed to operate in parallel with a public low voltage distribution network"[15]. Pepermans et al. [20] reviewed that many definitions suggest that at least the small scale generation units connected to the distribution grid are to be considered as part of DG. Moreover generation units installed close to the load or at the customer side of the meter are also commonly identified as DG. Pepermans et al. also argue that generation units should by definition at least supply active power in order to be considered as DG. The supply of reactive power and/or other ancillary services is possible and may represent an added value but is not 


\section{International Journal of Science and Research (IJSR) \\ ISSN (Online): 2319-7064 \\ Index Copernicus Value (2013): 6.14 | Impact Factor (2014): 5.611}

necessary. The deployment of DG is growing worldwide. For example the global off grid photovoltaic (PV) market is currently experiencing a growth rate of $20 \%$ per year [11] the cumulative capacity being $150 \mathrm{MWp}$ in 2007. Many had described that micro-generation technologies have attracted increasing attention as potential future energy technologies. Interest in micro -generation is also growing in government circle with UK Department for Trade and Industry (DTI) suggesting that by 2050 around $40-50 \%$ of the country's energy needs could be met by micro-generation technologies [15].

\subsection{Distributed vs. centralized electricity generation}

Under the current centralized generation paradigm electricity is mainly produced at large generation facilities shipped though the transmission and distribution grids to the end consumers. However the recent quest for energy efficiency and reliability and reduction of greenhouse gas emissions led to explore possibilities to alter the current generation paradigm and increase its overall performances. In this context one of the best candidates to complement or even replace the existing paradigm is distributed generation where electricity is produced next to its point of use [18].

Several studies were conducted to emphasize the main shortfalls of the centralized generation paradigm and to explicit the motivation of the gents in keeping distributed generation as a primary source of electricity or as a backup generator [18],[20]. The main drivers listed in the literature are summarized below:

\section{- Transmission and distribution costs}

Transmission and distribution costs amount for up to $30 \%$ of the cost of delivered electricity on average. The lowest cost is achieved by industrial customers taking electricity at high to medium voltage and highest for small customers taking electricity from the distribution network at low voltage [21]. The high price for transmission and distribution results mainly from losses.

\section{- Rural Electrification}

In an integrated power system rural electrification is challenging for two reasons. As large capital expenditures are required to connect remote areas due to the distance to be covered through overhead lines connecting remote areas with small consumption might prove uneconomical. This effect is amplified when taking into account transmission and distribution losses because both tend to increase with the distance covered. Rural electrification is thus costly.

Over the next 20 years significant investment will be required to upgrade the transmission and distribution networks. The International Energy Agency (2003) [24] estimated the total amount to be invested in generation transmission and distribution up to 2030 for the Organization for Economic Co-operation \& Development (OECD) countries to stands between 3,000 and 3,500 billion dollars (base case predictions). In order to cut these costs distributed generation can be used as a way to bypass the transmission and distribution networks in its alternative scenario. Under this scenario distributed generation and renewable energy are more heavily supported by policy makers the IEA forecasts the overall amount to be invested to be lower than 3,000 billion dollars (electricity generation investments remaining constant).

\section{- Energy efficiency}

In the 1960s the marginal gains in energy efficiency through size increase and use of higher temperature and pressure started to diminish. Higher temperatures and pressure resulted in high material wear and tear leading to lower than expected operating life for steam turbines [18]. In order to increase energy efficiency without requiring to higher pressure cogeneration systems have been developed to reuse the waste steam in a neighborhoods heating system or cooling system through district heating and/or cooling district. The total energy efficiency achieved when combining both electricity and heat goes up to $90 \%$.

Comparatively the sole electricity generation hardly goes above $40 \%$. The main problem however is that steam and heat are even less easily transported than electricity thus justifying the use of distributed generation through production next to the point of consumption [18].

\section{- Security and reliability}

The persistence of distributed generation contributed to energy security through two effects, fuel diversity and back up generation. As distributed generation technologies can accommodate a larger range of fuel that centralized generation distributed generation has been used to diversify away from coal fuel natural gas and nuclear fuel (IEA, 2002)[21]. For instance distributed generation has been used at landfills to collect biogas and generate energy. For back up generation, the main use of distributed generation is for back up capacities to prevent operational failures in case of network problems. Backup generators have been installed at critical location such as hospitals.

\section{- Environmental Impact}

The environmental impact of the centralized energy system is significant due to the heavy reliance on fuel, coal and to a lesser extent natural gas. The electricity sector is responsible for $1 / 4$ of the NOx emissions, $1 / 3$ of the $\mathrm{CO} 2$ emissions and $2 / 3$ of the SO2 emissions in the United States (EPA, 2003). Distributed generation has been used to mitigate the impact both in terms of emissions associated with transmission and distribution losses to increase efficiency through cogeneration and distributed renewable energy.

\subsection{Technologies Used For Distributed Generation}

The variety of end-use is to be related to an even greater variety in technologies. The range of technologies used for distributed generation and described by the International Energy Agency [21] includes, reciprocating Engines, renewable sources, gas turbines and microturbine.

Reciprocating engines technology uses compressed air and fuel. The mixture is ignited by a spark to move a piston. The

\section{Volume 5 Issue 7, July 2016




\section{International Journal of Science and Research (IJSR) \\ ISSN (Online): 2319-7064}

Index Copernicus Value (2013): 6.14 | Impact Factor (2014): 5.611

mechanical energy is then converted into electrical energy. Reciprocating engines are a mature technology and largely spread thank to their low capital invest requirement, fast start-up capabilities and high energy efficiency when combined with heat recovery systems. Most reciprocating engines run either on fuel or natural gas with an increasing number of engines running on biogas produced from biomass and waste. On the rolling year June 2007- May 2008 most of the reciprocating engines ordered were used as back-up or stand-by generators $(45 \%)$ the remaining being divided between peaking generators $(30 \%)$ and continuous generators $(25 \%)[18]$. Reciprocating engines perform however poorly in terms of noise, maintenance and emissions [21].

Gas Turbines are widely used for electricity generation and this trend has been encouraged by the regulatory incentives induced to favor fuel diversification towards natural gas and which has lower emission levels. Conversely to reciprocating engines gas turbines ordered over the period covered by the survey were widely used as continuous generators (58\%), $18 \%$ were used as standby generators and $24 \%$ as peaking generators [18]. Gas turbines are widely used in cogeneration.

The renewable energy sources include photovoltaic technologies, wind energy, thermal energy etc. These sources qualify as distributed generation only if they meet the criteria of the definition which is not always the case. Distributed generation is therefore clearly distinct from renewable energy. For example offshore wind farms do not qualify as distributed generation.

\subsection{Challenges of Sharing the DG}

\subsubsection{Location and Size}

High levels of penetration of distributed generation (DG) are a new challenge for traditional electric power systems. Power injections from DGs change network power flows modifying energy losses and voltage profile of the system. Proper locations of DGs in power systems are extremely important in order to obtain maximum potential benefits. A method for solving distributed generation planning problem (location and size) in different utility scenarios as an optimization problem is proposed in reference [11],[12],[13].In [12] authors give a global performance index (GPI) considering a wide range of technical issues for distribution networks with distributed generation. Many indices related to involvement of (DG) units in distribution system can be considered individually but a global performance index (GPI) has to be obtained to give a complete comprehensive concept of the whole system. Distributed generations are extensively located and sized within a test system where in the global performance index is computed for each configuration in order to assign the best locations of the DGs. [11] investigated the transmission system transient stability is when a fault is applied in all possible branches. In this study the penetration level of DG implementation is raised in two ways, load increase is covered by DG implementation and reduction of centralized generation is covered by DG. [14] Proposed method combining optimal power flow and genetic algorithms to define the optimal locations and capacities of distributed generation. In [15] authors give methodology for optimal value of the DG capacity to be connected to the existing system. The proposed work aims at minimizing the combined objective function designed to reduce power loss and also improve system performance for various values of distributed generations.

\subsubsection{System Performance}

The overall problem when integrating DG in existing networks is that distribution systems are planned as passive networks carrying the power unidirectional from the central generation ( $\mathrm{HV}$ level) downstream to the loads at MV/LV level. The protection system design in common MV and LV distribution networks is determined by a passive paradigm, i.e. no generation is expected in the network. With distributed sources the networks get active and conventional protection turns out to be unsuitable. Various impacts of DG connection on existing utility network protection are listed below:

False tripping of feeders

- Nuisance tripping of protective devices

o Blinding of protection

O Increase or decrease of fault levels with connection and disconnection of DERs

o Unwanted islanding

- Prevention of automatic reclosing

○ Unsynchronized reclosing

[17] Give some light on the impact of DGs on voltage regulation and on over current protection. These impacts are investigated on a feasibility study concerning the installation of a $5 \mathrm{MW}$ grid-tied PV system to a local distribution system. [18] Present an adaptive distributed power flow solution method based on the compensation-based method. The comprehensive distributed system model includes 3phase nonlinear loads, lines, capacitors, transformers, and dispersed generation units. The numerical properties of the compensation-based power flow method are compared and analyzed under different situations such as load unbalance, sudden increase of 1-phase loads, degree of meshed loops, number of generator nodes and so on. Analysis of dynamic performance of DG connected through inverter to distribution networks under abnormal operating conditions is done by [19].

\subsubsection{Short Circuit Power and Fault Current Level}

The phase-phase or phase-earth faults current normally result in an overcurrent which is significantly higher than the operational or nominal current. This is a very basic precondition for the function of (instantaneous) overcurrent protection. The fault current has to be distinguishable from the normal operational current. To fulfill that there has to be a powerful source providing a high fault current until the relay triggers. This is not the case for all kinds of generation devices. Especially power electronic converters are often equipped with controllers that prevent high currents. If for example a remote part of a distribution network is equipped with large PV installations it could happen that in case of a failure there is almost no significant rise of the phase current 


\section{International Journal of Science and Research (IJSR) \\ ISSN (Online): 2319-7064 \\ Index Copernicus Value (2013): 6.14 | Impact Factor (2014): 5.611}

and the fault is therefore not detected from the overcurrent protection system. The question arises why one needs to care about a fault if there is no fault current. The answer is that dangerous touch voltages may occur even if the current is low. Furthermore permanent faults may spread out and destroy more equipment.

\subsubsection{Reduced Reach of Impedance Relays}

The reach of an impedance relay is the maximum fault distance that triggers the relay in a certain impedance zone or in a certain time due to its configuration. This maximum distance corresponds to a maximum fault impedance or a minimum fault current that is detected. With DG the impedance measured by the relay is higher than the real fault impedance (as seen from relay) what corresponds to an apparently increased fault distance. Consequently the relay may trigger in higher grading time response in another distance zone.

\subsubsection{Reverse Power Flow and Voltage Profile}

Radial distribution networks are usually designed for unidirectional power flow from the infeed downstream to the loads. This assumption is reflected in standard protection schemes with directional overcurrent relays. With a generator on the distribution feeder the load flow situation may change. If the local production exceeds the local consumption, power flow changes its direction. Reverse power flow is problematic if it is not considered in the protection system design. Moreover reverse power flow implies a reverse voltage gradient along a radial feeder. Dispersed generation always affects the voltage profile along a distribution line. Beside power quality issues this could cause a violation of voltage limits and cause additional voltage stress for the equipment. The installation of distributed generation on distribution feeder is known to have an impact on the voltage regulation. A DG can provide voltage support in some cases but can also cause an overvoltage or an undervoltage depending on the several variables including relative DG size and location, distribution line and load characteristics and method of voltage regulation.

In the absence of DG the action of centralized voltage control devices depends on the fact that the voltage profile decreases along the feeders. With the introduction of DG resources voltages are no longer decreasing along the feeders so that the control strategies already in use need to be revisited. New functions have been proposed to adapt the voltage set point at the HV/MV supply substation on the basis of voltage values or other information measured or estimated at specific points of the distribution network in some cases extending the Line Drop Compensation (LDC) method. Getting the information needed to ensure a coordinated control requires setting up a suitable communication system between different points of the distribution system. However the increasingly higher penetration of DG sources owned and managed by different subjects may lead to difficulties in setting up properly coordinated controls. The possible effects of lack of coordination among local control and centralized control at the HV/MV supply substations as well as the identification of suitable strategies to improve the level of coordination are challenging open fields of research [20].

\subsubsection{Islanding and Auto Reclosure}

Islanding is a condition in which a portion of the utility system which contains both load and generation is isolated from the remainder of the utility system and continues to operate. The isolation point is generally on the low voltage distribution line when an islanding condition exists but islanding may also occur on the higher voltage distribution or transmission lines when large numbers of PV inverters or other distributed generation is present. [21] Give an islanding detection approach for the dispersed generator with selfcommutated static power converter is proposed. This method is suggested based on the monitoring of the magnitude and sign change in $\frac{\partial f_{B}}{\partial P_{L}}$. To facilitate the detection process a designated circuit for generating the output power deviation is also developed. [22] Present a new algorithm based on the monitoring of the change in $\frac{\partial f}{\partial P_{L}}$ to detect the islanding is proposed. By the proposed method a detection index can be evaluated that serves as a useful reference to activate the protective relays. This approach has been applied to investigate different scenarios including the loss of grid and the parallel operation. Effects of load change and powerquality disturbances to the detection performance are also examined.

Anti-islanding protection schemes currently enforce the DGs to disconnect immediately for grid faults through loss of grid (LOG) protection system. This greatly reduces the benefits of DG deployment. For preventing disconnection of DGs during LOG several islanding protection schemes are being developed. Their main objectives are to detect LOG and disconnect the DGs from the utility. This allows the DGs to operate as power islands suitable for maintaining uninterruptible power supply to critical loads. A major challenge for the islanding protection schemes is the protection co-ordination of distribution systems with bidirectional fault current flows. This is unlike the conventional overcurrent protection for radial systems with unidirectional fault current flow [16]. This work presents a comprehensive survey of various islanding protection schemes that are being developed tested and validated through extensive research activities across the globe.

Islanding and reclosing problems are closely linked together. DG may continue operation during the auto reclose open time, sustaining voltage and feeding fault current. Thus it may prevent fault arc extinction. This leads to unsuccessful reclosure and the fault that would have been temporary becomes permanent. By preventing successful reclosing DG may deteriorate the reliability of network and increase the number of customer minutes lost. Unsuccessful reclosing attempt also increases stress to network component because the reclosing circuit breaker will be closed against a fault. DG units should be disconnected clearly before the reclosure so that there will be enough time for arc extinction and arc path dissipation. Otherwise the arc will reignite immediately 


\section{International Journal of Science and Research (IJSR) \\ ISSN (Online): 2319-7064 \\ Index Copernicus Value (2013): 6.14 | Impact Factor (2014): 5.611}

after reclosing. More severe problem may occur when DG units are not tripped during the auto reclose open time. The generators can accelerate or decelerate so that reclosure occurs at moment when the voltages in the islanded part of the network and in the main grid are in phase opposition. This can have severe consequences (overvoltage, overcurrent and large mechanical torque are possible).

[26] Investigates preplanned switching events and fault events that lead to islanding of a distribution subsystem and formation of a micro-grid.

\subsection{The Dispersed Generation Concept in the Sudan}

Sudan's electrical power sector has been subject to poor infrastructure and experiences frequent power outages. At present the country's electricity generating capacity consists of about 760 megawatts of thermal power, about 320 megawatts of hydropower capacity, and total electricity generation is 3.2 billion kilowatt hours (Bow). About $70 \%$ of the electricity is consumed in the Khartoum area. Rural areas are without access to electricity, except for some large, export-oriented agricultural schemes. Electrical power is transmitted through two interconnected electrical grids, the Blue Nile Grid and the Western grid, which encompasses a small portion of the country. Regions in Sudan that are not covered by the grid rely on small diesel-fired generators for power. Only 30 percent of Sudan's population currently has access to electricity, the government hopes to increase that figure to 90 percent in the near future.

Dispersed generation (DG) in the Sudan is an interesting concept, particularly if it is deploying renewable energy technology.

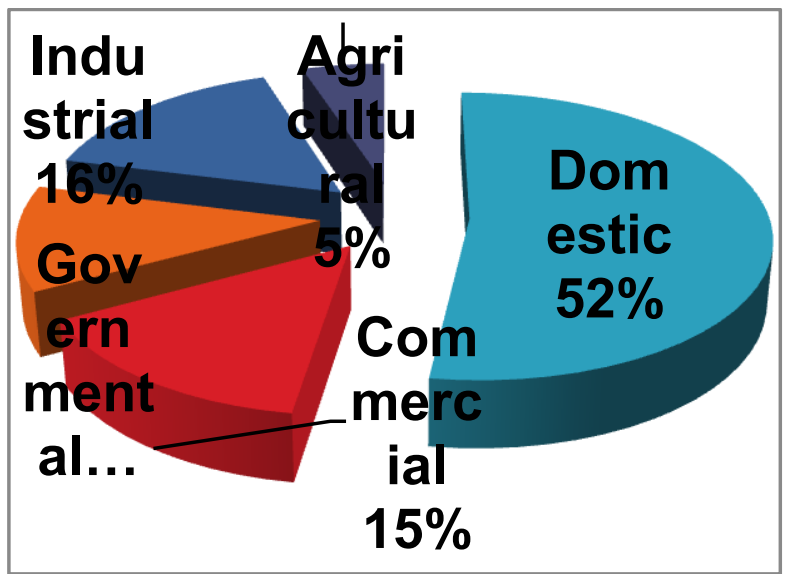

Figure 1: Electrical Energy Consumption by Sector-(2012)

\subsubsection{Renewable Energy in the Sudan}

Sudan has difference kind of natural resource of renewable energy including solar energy which can be found in most areas of Sudan and wind in the Red Sea, north of Sudan and the Darfur region in western Sudan. Great sources of biomass are also available and Geothermal Energy in the areas of Jebel Mara, Sahara desert and the Red Sea in eastern Sudan.
Average annual wind speeds in Sudan ranges from $4.2 \mathrm{~m} / \mathrm{s}$ and $8.1 \mathrm{~m} / \mathrm{s}$. The areas with the highest wind speeds are northern Sudan, the Red Sea area and the western Sudan.

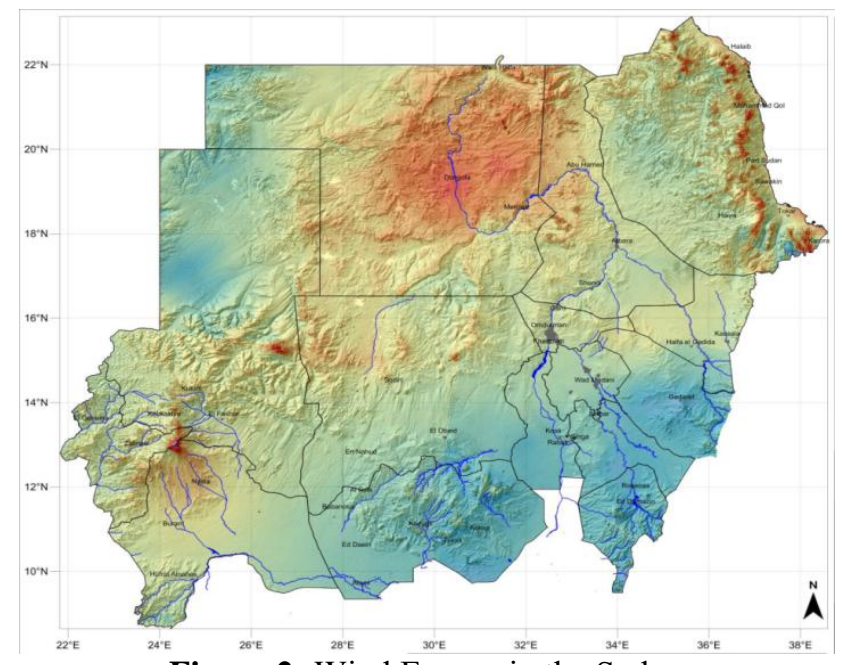

Figure 2: Wind Energy in the Sudan

The average daily solar radiation ranging between 5.8 and 7.2 kilowatt hours per square meter. Solar radiation is available in almost all regions of Sudan and it increase in the North, decrease as we go to the south.

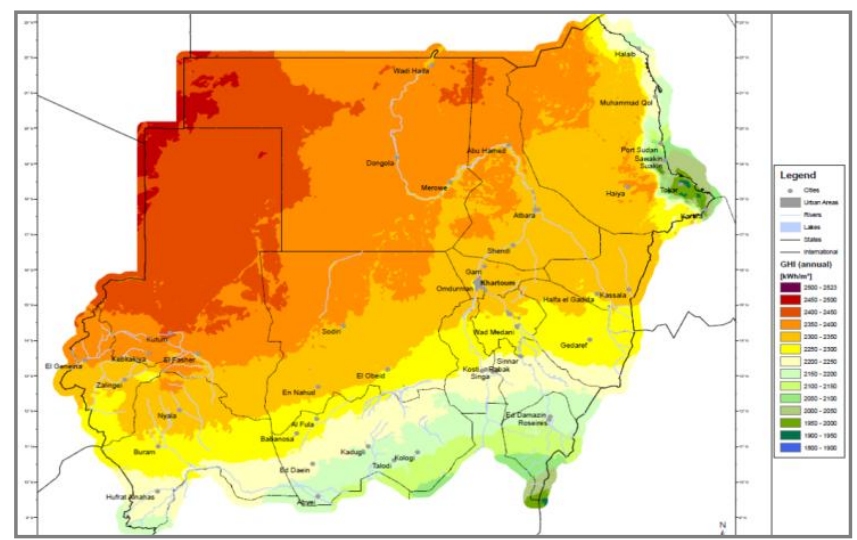

Solar Energy in the Sudan

Sudan has a large-water resources which helped him to carry large agricultural projects like Gezira Scheme and it extend. The work studies were done to take advantage of irrigation canals and waterfalls in the generation of electricity by small hydro-generation technology. Studies have proved that there is a possibility to generate electricity through an economic $y$ technology in many locations with a total capacity $56 \mathrm{MW}$.

Sudan has a small scale power plants which may be consider as distributed generation in rural area and offset of the grid. 


\section{International Journal of Science and Research (IJSR) \\ ISSN (Online): 2319-7064}

Index Copernicus Value (2013): 6.14 | Impact Factor (2014): 5.611

Table 1: Off-grid Power Station

\begin{tabular}{|c|c|c|c|c|c|}
\hline Name & Fuel Type & $\begin{array}{l}\mathrm{N}^{0} \text { of } \\
\text { units }\end{array}$ & $\begin{array}{c}\text { Total } \\
\text { Capacity } \\
\text { [MW] }\end{array}$ & $\begin{array}{c}\text { Connected } \\
\text { Voltage } \\
{[\mathrm{Kv}]}\end{array}$ & Remarks \\
\hline \multirow{3}{*}{ Alfashir old } & & 4 & 5.2 & 33 & operational \\
\hline & \multirow[t]{2}{*}{ Diesel } & 4 & 2.4 & 33 & operational \\
\hline & & 3 & 9.6 & 33 & operational \\
\hline \multirow{4}{*}{$\begin{array}{l}\text { Alginena } \\
\text { Alnohood } \\
\text { Aldhain }\end{array}$} & \multirow{4}{*}{$\begin{array}{l}\text { Diesel } \\
\text { Diesel } \\
\text { diesel }\end{array}$} & 5 & 7.85 & 33 & operational \\
\hline & & 4 & 4.8 & 33 & Operational \\
\hline & & 2 & 2 & 11 & operational \\
\hline & & 4 & 11.12 & 11 & operational \\
\hline \multirow{4}{*}{ Nyala } & \multirow{4}{*}{ Diesel } & 3 & 4.8 & 11 & operational \\
\hline & & 4 & 8 & 11 & operational \\
\hline & & 3 & 3.6 & 11 & operational \\
\hline & & 2 & 3 & 11 & operational \\
\hline Portsudan & Diesel & 7 & 37.65 & 11 & operational \\
\hline
\end{tabular}

Table 2: On-Grid Power Station

\begin{tabular}{|c|c|c|c|c|c|}
\hline Name & Fuel Type & $\begin{array}{c}\mathrm{N}^{\circ} \text { of } \\
\text { units }\end{array}$ & $\begin{array}{c}\text { Total } \\
\text { Capacity } \\
{[\mathrm{MW}]} \\
30.4\end{array}$ & $\begin{array}{c}\text { Connected } \\
\text { Voltage } \\
{[\mathrm{Kv}]} \\
33\end{array}$ & Remarks \\
$\begin{array}{c}\text { Jebel Aulia } \\
\text { Sennar }\end{array}$ & $\begin{array}{c}\text { Hydro } \\
\text { hydro }\end{array}$ & $\begin{array}{c}80 \\
2\end{array}$ & $\begin{array}{c}110 \\
\text { operational } \\
\text { operational }\end{array}$ \\
\hline $\begin{array}{c}\text { Khasm } \\
\text { Elgirba } \\
\text { New Burri }\end{array}$ & hydro & 2 & 15 & 66 & $\begin{array}{c}\text { operational } \\
\text { Not }\end{array}$ \\
\hline Burri & Gas & 2 & 50 & 110 & $\begin{array}{c}\text { Not } \\
\text { operational }\end{array}$ \\
\hline Koko & Gas & 2 & 20 & 110 & $\begin{array}{c}\text { Not } \\
\text { operational }\end{array}$ \\
\hline
\end{tabular}

Some industries generate electrical power independently from the national power grid to cover their power consumption. These industries have their own power plants like Sugar and Oil and Gas industries.

It is more effective for these power stations work with some kind of renewable power plant in micro-grid and connected it to the national grid.

\section{Results \& Discussion}

We can put some criteria to help for definition of DG:

- Voltage level at grid connection

Although some authors allow distribution generation to be connected to the transmission grid most authors see DG as being connected to the distributed network either on the distribution or on the consumer side of meter. In all cases the idea is accepted that DG should be located closely to the load. The problem is that a distinction between distribution and transmission grid is not always useful because of the existing overlap of these voltage levels for lines in the transmission and distribution grid. Moreover the legal voltage level that distinguishes distribution from transmission can differ from region to region. It would be more appropriated to use the concept distribution network and transmission network to refer to the legal [definition of these networks as they are used in the country under consideration.

\section{- Generation capacity}

One of the most obvious criteria would be the generation capacity of the units installed. However the short survey of definitions illustrated that there is no agreement on maximum generation capacity levels and the conclusion is that generation capacity is not a relevant criterion. The major argument is that the maximum DG capacity that can be connected to the distribution grid is a function of the capacity of the distribution grid itself. Because this latter capacity can differ widely it is not possible to include it as an element of the definition of DG. However this does not imply that the capacity of the connected generation units is not important.

\section{- Services supplied}

Generation units should by definition at least supply active power in order to consider as distributed generation. The supply of reactive power and/or other ancillary series is possible and may represent an added value but is not necessary.

\section{- Generation Technology}

In some cases it can be helpful to clarify the general definition of distributed generation by summing up the generation technologies that are taken into. It would however be difficult to use this approach to come to a definition because the availability of technologies and of capacities especially in the field of renewable differs between countries. Also conventional systems such as gas turbines are available over wide range.

Ackermann et al. [22] do not consider the operation mode (being scheduled, subject to pool pricing, dispatchable ....) as a key element in the general definition of DG. This is a correct view but at the same time it must be recognized that many of the problem related to DG essentially have to do with the fact that these generation units are beyond control of grid operators. So it can be meaningful to use the operation mode as a criterion to narrow the definition.

\section{- Power delivery area}

In some cases distributed generation is described as power that is generated and consumed within the same distribution network. As correctly stated by Ackermann et al. [22] it would be difficult to use this as a criterion.

\section{- Ownership}

Ackermann et al. [22] do not consider ownership as a relevant element for the definition of distributed generation. Thus customers and traditional generators company can own distributed generation units.

\section{Conclusions}

The recent attention paid to distributed generation is not surprising in many ways. The flaws of the centralized generation paradigm led to look for a complement generation technique, a role that was endorsed to the extent possible by the distributed generators before the energy deregulation. First technical issues will need to be solved is better understanding of the impact of a high number of distributed generators need to be developed and network management procedures will have to be overhauled to fully exploit its implicit benefits. 


\section{International Journal of Science and Research (IJSR) \\ ISSN (Online): 2319-7064 \\ Index Copernicus Value (2013): 6.14 | Impact Factor (2014): 5.611}

Small-scale generation is commonly called distributed generation and we try to derive a consensus definition for this latter concept. It appears that there is no agreement on a precise definition as the concept encompasses many technologies and many applications in different environments. In our view, the best definition of distributed generation that a small electric generation plant that provided at least active power, connected close to loads and these generation units are beyond of grid operator (scheduled, dispatch able, subjected to pool pricing ....). A further narrowing of this definition might be necessary

\section{References}

[1] Sylvain Martel, Dave Turcotte, "Review of distributed generation product and interconnection standards for Canada " IEEE Electrical Power conference, Quebec, 25 26 October, Canada 2007

[2] G. Pepermans, J. Driesen, D. Haeseldonckx, R.Belmans, W. D'haeseleer, "Distributed Generation: Definition, Benefits And issues" Energy Policy 33, pp 787 - 798, 2005

[3] International Energy Agency ( IEA), Distributed Generation in Liberalised Electricity Markets, Paris, p. 128, 2002

[4] Indradip Mitra, Thomas Degner and Martin Braun, " Distributed Generation and Microgrids for Small Island Electrification in Developing Countries: A review" SESI Journal, vol. 18, $\mathrm{N}^{\mathrm{o}}$ 1, pp 6-20, 2008

[5] Ackermann, T., Andersson, G. and Soder, L., "Distributed Generation: A Definition" Electric Power Systems Research, 57, pp. 195-204, 2001

[6] James A. Momoh , Yan Xia and Garfield D. Boswell " An Approach to Determine Distributed Generation (DG) Benefits in Power Networks " Power system symposium NAPS '08' 40 ${ }^{\text {th }}$ North American, pp 1-7, 28-30 Sept. 2008

[7] Debabrata Kundu "An Overview of the Distributed Generation (DG) Connected to the GRID "Power system technology \& IEEE Power India Conference, POWERCON, Joint international conference, pp 1-8, 12-15 Oct. 2008

[8] M. Reza, Schavemaker, J. G. Slootweg, W. L. Kling, and L. van der Sluis "Impacts of Distributed Generation Penetration Levels on Power Systems Transient Stability " IEEE Power Engineering Society, General Meeting vol. 2, pp 2150 - 2155, 10 - June 2004

[9] Jeremi Martin, Antoine Hyafil, "Distributed vs. centralized electricity generation: are we witnessing a change of paradigm?"'HEC Paris, martinjeremie@hotmail.com, May 2009

[10] International Energy Agency, "Distributed Generation and Renewables Outlook 2030, (http://www.iea.org/textbase/work/2004/distgen/Birol.pdf)

[11] M. Reza, Schavemaker, J. G. Slootweg, W. L. Kling, and L. van der Sluis "Impacts of Distributed Generation Penetration Levels on Power Systems Transient Stability " IEEE Power Engineering Society, General Meeting vol. 2, pp 2150 - 2155, 10 - June 2004

[12] Hussein A. Attia, Zeinab H. Osman, M. El shinini, and Ahemed A. moftah ,"An assessment of distribution generation Impacts on Distribution Networks using Global Performance Index " Nature and Science, 8(9), pp 150 158,2010

[13] M. F. Akorede, H. Hizam, I. Aris and Z. M. A. Ab Kadir, "A review of strategies for optimal placement of DG in power distribution systems" Research Journal of Applied Sciences, 5(2), pp 137 - 145, 2010

[14] Gareth P. Harrison, Antonio Piccolo, Pierluigi Siano, A. Robin Wallace, "Distributed Generation Capacity Evaluation Using Combined Genetic Algorithm and OPF " International Journal of Emerging Electric Power Systems, vol.8, issue 2, article 7, 2007

[15] P. Ajay-D-Vimal Raj, S. Senthilkuma, J. Raja, S.Ravichandran and T. G. lanivelu," Optimization of Distributed Generation Capacity for Line Loss Reduction and Voltage Profile Improvement Using PSO" Elektrika, vol. 10, $\mathrm{N}^{\mathrm{o}} 2$, pp41- 48, Malaysia, 2008

[16] S.P.Chowdhury, S.Chowdhury, Chui Fen Ten and P.A.Crossley "Islanding Protection of Distribution Systems with Distributed Generators - A Comprehensive Survey Report" IEEE Power Engineering Society, General Meeting - Conversion and delivery of electrical energy in $21^{\mathrm{st}}$ centry, pp $1-8,2008$.

[17] Yahia Baghzouz, "voltage regulation and overcurrent protection issues in distribution feeder with DG" System Sciences, HICSS 05 Proceedings of the $38^{\text {th }}$ annual Hawaii international conference 2005

[18] Y. Zhu, K. Tomsouvic, "Adoptive power flow method for distribution systems with dispersed generation " IEEE transaction on Power Delivery, vol.17, $\mathrm{N}^{\mathrm{o}} 3$, July 2002

[19] Roberto Caldon, Fabrizio Rossetto, Roberto Turri, "Analysis of dynamic performance of dispersed generation networks" CIRED, $17^{\text {th }}$ international conference on Electricity Distribution, Barcelona, 12-15 may 2003

[20] Enrico Carpaneto, Gianfranco Chicco, Maurizio De Donno and Roberto Napoli "Voltage Controllability of Distribution Systems with Local Generation Sources" Bulk Power System Dynamics and Control - VI, August 22-27, 2004, Cortina d'Ampezzo, Italy

[21] Shyh-Jier Huang , Fu-Sheng Pai, " A New Approach to Islanding Detection of Dispersed Generators with SelfCommutated Static Power Converters " IEEE Transactions on Power Delivery, vol. 15, N ${ }^{\circ}$. 2, pp 500 - 507, April 2000

[22] Fu-Sheng Pai and Shyh-Jier Huang, "A Detection Algorithm for Islanding- revention of Dispersed ConsumerOwned Storage and Generating Units" IEEE transaction on Energy conversion, vol. 16, $\mathrm{N}^{\mathrm{0}} 4$, pp 346 - 351, December 2001.

[23] Zhenhua Jiang, Xunwei Yu"Active Power-Voltage Control Scheme for Islanding Operation of Inverter-Interfaced Microgrid"

[24] Debabrata Kundu "An Overview of the Distributed Generation (DG) Connected to the GRID "Power system technology \& IEEE Power India Conference, POWERCON, Joint international conference, pp 1-8, 12-15 Oct. 2008

[25] A. Bertani, C. Bossi, F. Fornari, S. Massucco, S. Spelta and F. Tivegna, " A microturbine Generation system for grid connected and Islanding Operation" IEEE PSCE, New york, October 10-13, 2004

[26] F. Katiraei, M. R. Iravani, and P. W. Lehn," Micro-Grid Autonomous Operation During and Subsequent to Islanding Process" IEEE Transactions on Power Delivery, vol. $20, \mathrm{~N}^{0} 1$, pp 248-257, January 2005

[27] https://prezi.com/nqqjwrqdwosi/copy-of-power- plant insudan

[28] "Hydroelectric Power Plants in Egypt \& Sudan" Gallery. Power Plants around the World, 2 March 2013. Retrieved 1 March 2014 